\title{
The Association Between History of Depression and Access to Care Among Medicare Beneficiaries During the COVID-19 Pandemic
}

\author{
Lilanthi Balasuriya, $\mathrm{MD}^{7}$, Jacob K. Quinton, MD, MPH' ${ }^{2}$, Maureen E. Canavan, PhD, MPH \\ Margaret L. Holland, PhD, MPH, MS $S^{4}$, E. Jennifer Edelman, MD, $M H S^{5,6}$, \\ Benjamin G. Druss, MD, MPH' and Joseph S. Ross, MD, MHS
}

\begin{abstract}
YYale National Clinician Scholars Program, Yale School of Medicine, New Haven, CT, USA; '2UCLA National Clinician Scholars Program, UCLA Department of General Internal Medicine, New Haven, CT, USA; ${ }^{3}$ Cancer Outcomes Public Policy and Effectiveness Research (COPPER) Center, Department of Internal Medicine, Yale School of Medicine, New Haven, CT, USA; ${ }^{4}$ Child Study Center, Yale School of Medicine, New Haven, CT, USA; ${ }^{5}$ Section of General Internal Medicine, Department of Internal Medicine, Yale School of Medicine, New Haven, CT, USA; ${ }^{6} \mathrm{Center}$ for Interdisciplinary Research on AIDS, Yale School of Public Health, New Haven, CT, USA; ${ }^{7}$ School of Public Health, Emory University, Atlanta, GA, USA; ${ }^{8}$ Department of Health Policy and Management, Yale School of Public Health, New Haven, CT, USA; ${ }^{9}$ Center for Outcomes Research and Evaluation, Yale-New Haven Hospital, New Haven, CT, USA.
\end{abstract}

BACKGROUND: Depression is associated with a higher risk for experiencing barriers to care, unmet social needs, and poorer economic and mental health outcomes.

OBJECTIVE: To determine the impact of COVID-19 on ability to access care, social and economic needs, and mental health among Medicare beneficiaries with and without depression.

DESIGN AND PARTICIPANTS: Cross-sectional study using data from the 2020 Medicare Current Beneficiary Survey COVID-19 Summer Supplement Public Use File.

MAIN MEASURES: Access to medical care, inability to access food, medications, household supplies, pay rent or mortgage, feelings of economic security, and mental health effects since COVID-19, risk-adjusted for sociodemographic and clinical characteristics.

KEY RESULTS: Participants were 11,080 Medicare beneficiaries (nationally representative of 55,960,783 beneficiaries), $27.0 \%$ with and $73.0 \%$ without a self-reported history of depression. As compared to those without a history of depression, Medicare beneficiaries with a selfreported history of depression were more likely to report inability to get care because of COVID-19 (aOR $=1.28$, 95\% CI, 1.09, 1.51; $P=0.003$ ), to get household supplies such as toilet paper $(\mathrm{aOR}=1.32,95 \% \mathrm{CI}, 1.10,1.58 ; P=$ $0.003)$, and to pay rent or mortgage $(\mathrm{aOR}=1.64,95 \% \mathrm{CI}$, $1.07,2.52 ; P=0.02)$. Medicare beneficiaries with a selfreported history of depression were more likely to report feeling less financially secure $(\mathrm{aOR}=1.43,95 \% \mathrm{CI}, 1.22$, $1.68 ; P<0.001)$, more stressed or anxious $(\mathrm{aOR}=1.68$, $95 \% \mathrm{CI}, 1.49,1.90 ; P<0.001)$, more lonely or sad (aOR = 1.97, 95\% CI, 1.68, 2.31; $P<0.001$ ), and less socially connected $(\mathrm{aOR}=1.27,95 \% \mathrm{CI}, 1.10,1.47 ; P=0.001)$.

CONCLUSION: A self-reported history of depression was associated with greater inability to access care, more unmet social needs, and poorer economic and mental health

Prior presentations: None

Received February 1, 2021

Accepted June 16, 2021

Published online August 17, 2021 outcomes, suggesting greater risk for adverse health outcomes during COVID- 19.

KEY WORDS: depression; health services research; stress; primary care; prevention.

J Gen Intern Med 36(12):3778-85

DOI: $10.1007 /$ s11606-021-06990-4

(C) This is a U.S. government work and not under copyright protection in the U.S.; foreign copyright protection may apply 2021

\section{INTRODUCTION}

Depression is a leading cause of disability in the USA and is associated with increased mortality and morbidity in older adults $^{1,2}$ and experiencing barriers to health care access. ${ }^{3,4}$ Older adults with depression are at higher risk for having more significant unmet social needs such as access to food and housing, as well as inability to get medications. ${ }^{5-8}$

Against the backdrop of the coronavirus disease 2019 (COVID-19) pandemic, there is growing concern that older patients with depression may experience worsening access to medical care, as well as increased unmet social needs. ${ }^{9,10}$ These trends may be compounded by historical disparities in access to care for patients with depression.,

Pandemic-related stressors are likely to impact multiple domains, including financial security, unmet social needs, and mental health. ${ }^{11,12}$ Older adults with depression may be more likely to experience the impacts of these stressors given their often smaller social networks, higher comorbidity rates, known disparities in access to care, and fixed incomes. ${ }^{4,9,10,13}$ Moreover, older adults may be more susceptible to the mental health impacts of the pandemic given their increased risk for suicide, social isolation, and misinformation. ${ }^{9,10,14}$ Given that older adults and patients with mental health conditions are at higher risk for mortality from COVID-19, it is imperative to understand differences in sources of information and 
protective measures utilized to ensure these populations are reached and are aware of precautionary guidelines.

Our objective was to determine the impact of COVID-19 on ability to access care, social and economic needs, and mental health among Medicare beneficiaries with and without a selfreported history of depression, as well as to characterize the sources of information and protective measures taken related to COVID-19. To mitigate the impacts of COVID-19 in at-risk older adults, it is vital to understand these potential risks and barriers to care among Medicare beneficiaries with and without a self-reported history of depression.

\section{METHODS}

\section{Data Source}

We conducted a cross-sectional analysis of de-identified nationally representative data from the 2020 Medicare Current Beneficiary Survey (MCBS) COVID-19 Summer Supplement Public Use File. ${ }^{15}$ The MCBS is a continuous, multipurpose nationally representative survey of current Medicare beneficiaries. In response to COVID-19, the MCBS released an outof-cycle and topic-specific public use file as a supplement to the typical MCBS, administered by phone in June and July 2020 to established MCBS participants. ${ }^{16}$ The Yale University School of Medicine's Human Investigation Committee found this study to be exempt. This study utilizes the Strengthening the Reporting of Observational Studies in Epidemiology (STROBE) reporting guideline for observational studies.

\section{Study Design and Population}

The analytic sample included individuals who completed the MCBS COVID-19 Summer 2020 survey and was composed of beneficiaries selected from the 2016, 2017, 2018, and 2019 cohorts. ${ }^{15,16}$ Our analytic sample included Medicare beneficiaries receiving benefits due to age as well as disability status.

\section{Main Independent Variable}

The main independent variable was a self-reported history of depression, including any time in the Medicare beneficiary's life ("ever") and was reported during the fall of 2019 survey wave. Medicare beneficiaries were asked if "a doctor or other health professional [ever] told you that you had depression?" Medicare beneficiaries were categorized into two categories, those with a self-reported history of depression and those without. The 2020 MCBS COVID-19 Summer Supplement was a stand-alone supplement surveying previous MCBS participants and reported previous responses for comorbidities (including depression) and health behaviors from respondents. The question assessed only self-reported history of depression and did not assess severity of the diagnosis nor whether depressive symptoms were present at the time that the survey was completed.

\section{Main Outcome Variables}

The primary outcome was ability to get care because of COVID-19. Medicare beneficiaries were specifically asked if they needed "medical care for something other than the coronavirus, but not get it because of the coronavirus outbreak?" If Medicare beneficiaries responded "yes" to this question, they were asked about their ability to receive specific types of services (Appendix Table 6).

\section{Secondary Outcome Variables}

Secondary outcomes included measures of social and economic need and self-reported mental health since COVID-19. Social and economic needs included inability "to get the food you want," "get medications," "get household supplies, such as toilet paper," and "pay rent or your mortgage." Response choices were framed as "able to," "unable to," or "have not needed;" these variables were dichotomized by combining "able to" and "have not needed," as compared to "unable to." Economic needs were also assessed by asking Medicare beneficiaries about their feelings of financial security. Mental health was measured with questions regarding feeling "stressed or anxious," "lonely or sad," and "socially connected" since the onset of COVID-19. These variables were recategorized into feelings of "more," "less," or "about the same" for each corresponding response option.

Additional secondary outcomes included sources of COVID-19 information and engagement in protective behaviors. Medicare beneficiaries were asked if they used the following sources for COVID-19 information including "traditional news sources including TV, radio, websites, and newspapers," "social media," "comments or guidance from government officials," "other webpages/internet," "friends or family members," and "health care providers." Participants were then asked, of the above-listed categories, "which of these sources do you rely on most?" The engagement in protective behaviors responses included whether Medicare beneficiaries "washed your hands for 20 seconds with soap and water," "used hand sanitizer," "avoided touching your face," "coughed or sneezed into a tissue," "wore a facemask when out in public," "cleaned or sterilized commonly touched surfaces," "avoided contact with sick people," "kept a six-feet distance," "avoided gathering with groups of 10 people or more," and "left your home for essential purposes only."

\section{Sociodemographic Variables and Clinical Characteristics}

Sociodemographic and clinical characteristic variables were reported for participants. Sociodemographic variables included age (categorized as $<65,65-74,>75$ years), sex (male, female), race/ethnicity (White non-Hispanic, Black non-Hispanic, Hispanic, other/unknown), annual household income (MCBS delineated categories of $<\$ 25,000,>\$ 25,000$, or refused), metropolitan/non-metropolitan residency, and census region (Northeast, Midwest, South, West). 
Clinical characteristics included health behaviors and comorbidities. The health behavior variable assessed tobacco use (cigarettes, cigars, and pipes), which was categorized into never, former, or current users. Comorbidity variables included self-reported history of hypertension, myocardial infarction, angina pectoris, congestive heart failure, other heart conditions (valve/rhythm), stroke/brain hemorrhage, high cholesterol, Alzheimer's/dementia, osteoporosis, hip fracture, any autoimmune condition, diabetes mellitus, or lung disease (defined as emphysema, asthma, or chronic obstructive pulmonary disease). All comorbidity variables were measured as dichotomous responses.

\section{Statistical Analysis}

We estimated sample characteristics and outcomes and performed unadjusted differences in proportions of respondents with and without a self-reported history of depression. All variables were categorical, and $\chi^{2}$ tests were utilized to analyze differences in proportions between Medicare beneficiaries with and without a self-reported history of depression.

Multivariable regression models were used to examine the association between self-reported history of depression and each of the primary outcomes (inability to get care because of the coronavirus) as well as for the secondary outcomes examining measures of social and economic need and mental health since COVID-19, adjusting for the sociodemographic and clinical characteristics defined above. Reported key clinical characteristics of interest found to be significantly different between groups $(P<0.05)$, and predetermined sociodemographic variables were included in the multivariable logistic regression model. Rate of missingness was $3.7 \%$ for income, $2.0 \%$ for smoking history, and less than $1.0 \%$ for all other covariates. Due to this low amount of missingness, complete case analysis was used.

All $P$ values were from 2 -sided tests. To account for multiple comparisons, a Bonferroni correction was used and statistical significance was considered to be $P<0.025$. Analyses were conducted using Stata statistical software 16.0 (StataCorp). MCBS recommended survey weights were used to adjust sample characteristics to be representative of the Medicare population.

\section{RESULTS}

A total of 11,114 Medicare beneficiaries participated in the 2020 Medicare Beneficiary Survey. Of these, 3019 (27.0\%) self-reported having a history of depression and $8061(73.0 \%)$ self-reported no history of depression; information was missing for 34 Medicare beneficiaries $(0.3 \%)$, excluding them from analyses. Our final unweighted analytic sample size was 11,080 Medicare beneficiaries, which when weighted is nationally representative of 55,960,783 Medicare beneficiaries.

Medicare beneficiaries with a self-reported history of depression were more likely to be less than 65 years of age $(31.2 \%$ vs $8.5 \%, P<0.001)$, female $(64.5 \%$ vs $51.4 \%$, $P<0.001)$, had larger proportions with annual household incomes of less than $\$ 25,000(41.7 \%$ vs $26.5 \%, P=$ $0.001)$, and larger proportions of current smokers $(19.2 \%$ vs $9.8 \%, P<0.001$ ) (Table 1 ). Medicare beneficiaries with a self-reported history of depression were also more likely to have clinical comorbidities such as a history of diabetes mellitus $(41.6 \%$ vs $30.8 \%, P<0.001)$ and lung disease $(29.1 \%$ vs $15.4 \%, P<0.001)$. Other medical conditions reported in the MCBS data that were associated with depression can be found in Table 1. There were no differences between the groups with respect to living in metropolitan areas $(80.2 \%$ vs $79.6 \%, P=0.64)$ or access to the internet $(83.2 \%$ vs $82.6 \%, P=0.46)$.

\section{Inability to Get Care Because of COVID-19}

Overall, $20.8 \%$ of Medicare beneficiaries experienced an inability to get care because of COVID-19, including $24.9 \%$ and $19.3 \%$ among those with and without a self-reported history of depression, respectively $(P<0.001)$. In adjusted multivariable regression analysis, those with a self-reported history of depression were more likely to report inability to get care because of COVID-19 when compared with those without a selfreported history of depression (adjusted odds ratio $[\mathrm{aOR}]=$ $1.28,95 \%$ CI, 1.09, 1.51; $P=0.003$ ) (Table 2).

\section{Social and Economic Needs}

Reports of unmet social and economic needs since COVID-19 for all Medicare beneficiaries included $1.6 \%$ of beneficiaries reporting an inability to pay for rent or mortgage, $12.2 \%$ being unable to get household supplies such as toilet paper, to $18.5 \%$ reporting feeling less financially secure. When compared to those without, Medicare beneficiaries with a self-reported history of depression had higher proportions of reporting unmet social and economic needs, including inability to get household supplies such as toilet paper $(\mathrm{aOR}=1.32,95 \% \mathrm{CI}$, $1.10,1.58 ; P=0.003)$, inability to pay rent or mortgage (aOR $=1.64,95 \% \mathrm{CI}, 1.07,2.52 ; P=0.02)$, and feeling less financially secure $(\mathrm{aOR}=1.43,95 \% \mathrm{CI}, 1.22,1.68 ; P<$ 0.001) (Table 3).

\section{Mental Health}

Poor mental health since COVID-19 was common, as $45.9 \%$, $23.1 \%$, and $36.9 \%$ of all Medicare beneficiaries reported feeling more stressed or anxious, lonely or sad, and less socially connected since COVID-19, respectively. When compared to those without, Medicare beneficiaries with a self-reported history of depression were more likely to report poorer mental health, including feeling more stressed or anxious $(\mathrm{aOR}=$ $1.68,95 \% \mathrm{CI}, 1.49,1.90 ; P<0.001)$, lonely or sad $(\mathrm{aOR}=$ $1.97,95 \% \mathrm{CI}, 1.68,2.31 ; P<0.001)$, and less socially connected since COVID-19 $(\mathrm{aOR}=1.27,95 \% \mathrm{CI}, 1.10,1.47 ; P=$ 0.001) (Table 3). 
Table 1 Sociodemographic and Clinical Characteristics of Medicare Beneficiaries With and Without a Self-reported History of Depression

\begin{tabular}{|c|c|c|c|c|}
\hline & \multicolumn{4}{|c|}{ Unweighted number (weighted \%)* } \\
\hline & $\begin{array}{l}\text { Total survey } \\
\text { population }\end{array}$ & $\begin{array}{l}\text { Medicare beneficiaries with self- } \\
\text { reported depression }\end{array}$ & $\begin{array}{l}\text { Medicare beneficiaries without self- } \\
\text { reported depression }\end{array}$ & $\begin{array}{l}P \\
\text { value }^{\dagger}\end{array}$ \\
\hline Unweighted, No. & 11,080 & 3019 & 8061 & \\
\hline Weighted, No. & $55,960,783$ & $15,114,367(27.0)$ & $40,846,416(73.0)$ & \\
\hline \multirow{2}{*}{\multicolumn{5}{|c|}{ Sociodemographic characteristics }} \\
\hline & \multicolumn{4}{|c|}{ Age group, y } \\
\hline$<65$ & 1895 (14.6) & $1073(31.2)$ & $822(8.5)$ & $<0.001$ \\
\hline $65-74$ & $3964(53.3)$ & $970(46.8)$ & $2994(55.7)$ & \\
\hline \multirow{2}{*}{\multicolumn{5}{|c|}{$5221(32.1)$}} \\
\hline & & & & \\
\hline Female & $6110(54.9)$ & $1933(64.5)$ & $4177(51.4)$ & $<0.001$ \\
\hline $\begin{array}{l}\text { Race/ethnicity } \\
\text { White non-Hisnanic }\end{array}$ & & & & \\
\hline White, non-Hispanic & $\begin{array}{l}8246(75.7) \\
1097(10.0)\end{array}$ & $2179(74.7)$ & $6067(76.1)$ & $<0.001$ \\
\hline $\begin{array}{l}\text { Black, non-Hispanic } \\
\text { Hispanic }\end{array}$ & $1097(10.0)$ & $270(8.8)$ & $827(10.4)$ & \\
\hline Hispanic & $1123(8.0)$ & $392(10.1)$ & $731(7.2)$ & \\
\hline Other/Unknown & $614(6.4)$ & $178(6.4)$ & $436(6.4)$ & \\
\hline \multicolumn{5}{|l|}{ Residence } \\
\hline \multirow{2}{*}{\multicolumn{5}{|c|}{ Census region }} \\
\hline & & & & \\
\hline Northeast & 1910 (17.9) & $518(17.6)$ & $1392(18.1)$ & 0.60 \\
\hline Midwest & $2541(22.1)$ & $696(22.8)$ & $1845(21.8)$ & \\
\hline South & 4319 (38.2) & $1214(38.8)$ & $3105(37.9)$ & \\
\hline \multirow{2}{*}{\multicolumn{5}{|c|}{ Income group }} \\
\hline & & & & \\
\hline Less than $\$ 25,000$ & $4150(30.6)$ & $1535(41.7)$ & $2615(26.5)$ & 0.001 \\
\hline$\$ 25,000$ or more & $6435(65.7)$ & $1370(55.3)$ & $5065(69.5)$ & \\
\hline Missing & $495(3.7)$ & $114(3.0)$ & $381(4.0)$ & \\
\hline \multicolumn{5}{|l|}{ Comorbidities } \\
\hline Hypertension & $7111(62.8)$ & $1967(65.0)$ & $5144(62.0)$ & 0.02 \\
\hline Myocardial infarction & $1144(9.7)$ & $340(11.2)$ & $804(9.2)$ & 0.006 \\
\hline Angina pectoris & $944(8.3)$ & $304(10.0)$ & $640(7.7)$ & 0.002 \\
\hline Congestive heart failure & $723(5.7)$ & $281(8.6)$ & $442(4.7)$ & $<0.001$ \\
\hline $\begin{array}{l}\text { Other heart condition } \\
\text { (valve/rhythm) }\end{array}$ & $2570(21.6)$ & $745(23.8)$ & $1825(20.8)$ & 0.006 \\
\hline Stroke/brain hemorrhage & $1158(9.6)$ & $430(13.5)$ & $728(8.1)$ & $<0.001$ \\
\hline High cholesterol & $7093(64.8)$ & $2029(69.7)$ & $5064(63.0)$ & $<0.001$ \\
\hline Alzheimer's/dementia & $474(3.1)$ & $206(5.2)$ & $268(2.4)$ & $<0.001$ \\
\hline Osteoporosis & $2074(18.3)$ & $669(22.8)$ & $1405(16.7)$ & $<0.001$ \\
\hline Hip fracture & $427(3.2)$ & $149(4.6)$ & $278(2.6)$ & $<0.001$ \\
\hline Any autoimmune condition & $1981(18.8)$ & $783(27.5)$ & $1198(15.5)$ & $<0.001$ \\
\hline Diabetes mellitus & $3630(33.7)$ & $1201(41.6)$ & $2429(30.8)$ & $<0.001$ \\
\hline Lung disease & $2169(19.1)$ & $870(29.1)$ & $1299(15.4)$ & $<0.001$ \\
\hline \multicolumn{5}{|l|}{ Health behaviors } \\
\hline Cigarette/cigars/pipe never & 4694 (41.9) & $1176(37.1)$ & 3518 (43.6) & $<0.001$ \\
\hline user & & & & \\
\hline $\begin{array}{l}\text { Cigarette/cigars/pipe } \\
\text { former user }\end{array}$ & $4926(45.8)$ & $1213(43.7)$ & $3713(46.6)$ & \\
\hline $\begin{array}{l}\text { Cigarette/cigars/pipe } \\
\text { current user }\end{array}$ & $1228(12.3)$ & $563(19.2)$ & $665(9.8)$ & \\
\hline
\end{tabular}

*All percentages listed are weighted based on MCBS recommended survey weighting

$+P$ values are calculated from $\chi 2$ tests

\section{Sources of COVID-19 Information and En- gagement in Protective Measures}

Both Medicare beneficiaries with and without a self-reported history of depression reported the source relied upon most for COVID-19 information was traditional news sources (Table 4). Similarly, both groups of Medicare beneficiaries reported high levels of engagement in protective measures such as hand washing, mask wearing, hand sanitizer use, and keeping a six-feet distance (Table 5).

\section{DISCUSSION}

The COVID-19 pandemic has had wide-ranging impacts on individuals, communities, and public health, particularly vulnerable older adult populations. In our analysis of survey data from a nationally representative sample of Medicare beneficiaries collected in summer 2020, during the COVID19 pandemic in the USA, we found that a self-reported history of depression was associated with inability to access care because of COVID-19, as well as inability to get household supplies such as toilet paper, inability to pay rent or mortgage, feelings of less financial security, and poorer mental health. There was also high adherence to evidencebased COVID-19 protective measures, such as handwashing, social distancing, and mask wearing among both participants with and without a self-reported history of depression. Our findings suggest that older adults previously experiencing depression may be at greater risk for adverse health outcomes during COVID-19. 
Table 2 Inability to Get Care Because of COVID-19 Wanted Among Medicare Beneficiaries With and Without a Self-reported History of Depression

\begin{tabular}{|c|c|c|c|c|c|}
\hline & \multicolumn{5}{|l|}{ (Weighted \%) } \\
\hline & $\begin{array}{l}\text { Total survey } \\
\text { population }(\mathrm{n}= \\
\mathbf{1 1 , 0 8 0 )}\end{array}$ & $\begin{array}{l}\text { Medicare beneficiaries with } \\
\text { self-reported depression }(n= \\
\text { 3019) }\end{array}$ & $\begin{array}{l}\text { Medicare beneficiaries without } \\
\text { self-reported depression }(n= \\
\mathbf{8 , 0 6 1 )}\end{array}$ & $\begin{array}{l}\text { Adjusted odds } \\
\text { ratio }(95 \% \text { CI })^{\dagger}\end{array}$ & $\begin{array}{l}P \\
\text { value }\end{array}$ \\
\hline $\begin{array}{l}\text { Unable to get care } \\
\text { because of COVID- } \\
19\end{array}$ & 20.8 & 24.9 & 19.3 & $1.28(1.09,1.51)$ & 0.003 \\
\hline \multicolumn{6}{|c|}{$\begin{array}{l}\text { *All percentages listed are weighted based on MCBS recommended survey weighting } \\
\text { †For adjusted analysis, covariates included demographic characteristics such as age, sex, racelethnicity, annual household income, metropolitan } \\
\text { non-metropolitan residency, and census region; self-reported participant history of comorbidities including hypertension, myocardial infarction } \\
\text { angina pectoris, congestive heart failure, other heart conditions (valve/rhythm), stroke/brain hemorrhage, high cholesterol, Alzheimer's/dementia } \\
\text { osteoporosis, hip fracture, any autoimmune condition, diabetes mellitus, or lung disease; and health behaviors (tobacco use). All comorbidit) }\end{array}$} \\
\hline
\end{tabular}

This inability to access care during COVID-19 aligns with existing studies prior to COVID-19, which report that Medicare beneficiaries with mental health conditions experience decreased access to care, which may be related to historically lower quality of medical care, stigma, and structural determinants of health barriers. ${ }^{3,4,7,17}$ Patients may face the additive stigma and discrimination of having a mental health condition and concern for having COVID19. ${ }^{4,17}$ Prior literature has found that older patients may be unable to get care due to cost, and COVID-19 may present additional barriers including cancellation of appointments, fear of going to medical settings, challenges in navigating telehealth, or lack of safe transportation in light of social distancing guidelines. ${ }^{9,10,18-20}$ Addressing barriers to accessing care, which may lead to poorer health outcomes, is essential for older adults with mental health conditions who may have more complex care needs and are historically underserved. ${ }^{3,4,7,9,21}$

Medicare beneficiaries with a history of depression were at higher risk for having unmet social and economic needs in this pandemic, including inability to obtain household supplies, pay rent or mortgage, and feelings of less financial security. These findings remained significant after controlling for differences in income and geographic region. Even prior to COVID-19, higher unmet social and economic needs disproportionately impacted patients with mental health conditions. ${ }^{5,6,22}$ Our study's findings of both inability to access care and higher unmet social and economic needs in those with a self-reported history of depression are concerning for potential barriers to care and health that may influence morbidity and mortality. This is especially salient given the current higher rates of mortality seen in COVID-19 patients with mental health conditions. ${ }^{23,24}$

Table 3 Unmet Social and Economic Needs and Self-reported Mental Health Since COVID-19 Among Medicare Beneficiaries With and Without a Self-reported History of Depression

\begin{tabular}{|c|c|c|c|c|c|}
\hline & \multicolumn{5}{|l|}{ (Weighted \%) } \\
\hline & $\begin{array}{l}\text { Total survey } \\
\text { population }(n= \\
11,080)\end{array}$ & $\begin{array}{l}\text { Medicare beneficiaries with } \\
\text { self-reported depression }(n= \\
\text { 3019) }\end{array}$ & $\begin{array}{l}\text { Medicare beneficiaries } \\
\text { without self-reported depres- } \\
\text { sion }(n=8061)\end{array}$ & $\begin{array}{l}\text { Adjusted odds } \\
\text { ratio }(95 \% \mathrm{CI})^{\dagger}\end{array}$ & $\begin{array}{l}P \\
\text { value }\end{array}$ \\
\hline \multicolumn{6}{|c|}{ Unmet social and economic needs } \\
\hline $\begin{array}{l}\text { Unable to get the food } \\
\text { you wanted }\end{array}$ & 4.9 & 7.4 & 3.9 & $1.17(0.91,1.51)$ & 0.22 \\
\hline $\begin{array}{l}\text { Unable to get } \\
\text { medications }\end{array}$ & 1.9 & 2.8 & 1.6 & $0.97(0.64,1.47)$ & 0.88 \\
\hline $\begin{array}{l}\text { Unable to get household } \\
\text { supplies such as toilet } \\
\text { paper }\end{array}$ & 12.2 & 16.4 & 10.6 & $1.32(1.10,1.58)$ & 0.003 \\
\hline $\begin{array}{l}\text { Unable to pay for rent or } \\
\text { mortgage }\end{array}$ & 1.6 & 2.7 & 1.1 & $1.64(1.07,2.52)$ & 0.02 \\
\hline $\begin{array}{l}\text { Feel less financially } \\
\text { secure } \\
\text { Mental health }\end{array}$ & 18.5 & 24.7 & 16.2 & $1.43(1.22,1.68)$ & $<0.001$ \\
\hline $\begin{array}{l}\text { Feel more stressed or } \\
\text { anxious }\end{array}$ & 45.9 & 57.4 & 41.7 & $1.68(1.49,1.90)$ & $<0.001$ \\
\hline Feel more lonely or sad & 23.1 & 33.9 & 19.2 & $1.97(1.68,2.31)$ & $<0.001$ \\
\hline $\begin{array}{l}\text { Feel less socially } \\
\text { connected }\end{array}$ & 36.9 & 41.6 & 35.2 & $1.27(1.10,1.47)$ & 0.001 \\
\hline
\end{tabular}


Table 4 Source of COVID-19 Information Among Medicare Beneficiaries With and Without a Self-reported History of Depression

\begin{tabular}{llll}
\hline \hline & \multicolumn{2}{l}{$($ Weighted \%)* } & \\
\cline { 2 - 4 } & $\begin{array}{l}\text { Total survey population } \\
(\mathbf{n}=\mathbf{1 1 , 0 8 0})\end{array}$ & $\begin{array}{l}\text { Medicare beneficiaries with self- } \\
\text { reported depression }(\mathbf{n}=\mathbf{3 0 1 9})\end{array}$ & $\begin{array}{l}\text { Medicare beneficiaries without self- } \\
\text { reported depression }(\mathbf{n}=\mathbf{8 0 6 1})\end{array}$ \\
\hline $\begin{array}{l}\text { What sources of COVID-19 information were relied upon the most } \\
\text { Traditional news source }\end{array}$ & 58.3 & 53.9 & \\
Health care providers & 11.6 & 13.3 & 60.0 \\
Guidance from & 10.2 & 10.5 & 1.0 \\
government officials & & & 10.0 \\
Friends and family & 9.6 & 10.7 & 9.1 \\
members & 8.7 & 9.3 & 8.5 \\
Webpages/Internet & 1.6 & 2.3 & 1.4 \\
Social media & &
\end{tabular}

*All percentages listed are weighted based on MCBS recommended survey weighting

tParticipants were asked to select the one source they "rely on most" for information on COVID-19

Lastly, Medicare beneficiaries with a self-reported history of depression were at higher risk of reporting poor mental health during the COVID-19 pandemic, including reported feelings of more stress and anxiety, less social connectedness, and more loneliness or sadness than beneficiaries without a self-reported history of depression. This is consistent with prior literature that has found that in times of disaster, patients with mental conditions fare worse in regard to mental health outcomes. ${ }^{25}$ These poorer mental health responses seen in patients with a self-reported history of depression may reflect exacerbation of previous underlying depression. They may also be influenced by our findings of higher proportions of unmet social and economic needs, as the inability to access basic human needs such as toilet paper and pay for rent and mortgage likely impact both stress and mood.

Poorer mental health was seen in the entire Medicare beneficiary cohort since COVID-19, aligning with prior reported nationwide increases in mental health symptoms amidst the pandemic. ${ }^{26,27}$ One national study found that four in ten adults reported symptoms of anxiety or depression during the pandemic, which represents a stark increase from pre-pandemic rates of one in ten individuals in $2019 .{ }^{28}$ The rising rates of mental health symptoms in both those with and without a history of depression in Medicare beneficiaries is concerning particularly given risk factors associated with age, including higher suicide rates and social isolation. ${ }^{14}$

\section{Public Health and Policy Implications}

Depression, social isolation, lower socioeconomic status, and stigma are overlapping entities that interact with one another and may contribute to a cascade of disparities which warrant multi-level solutions. On a population health level, messaging via news sources may be effective. Key areas to highlight include when and how to access care, social resources, and the importance of social connectedness to mitigate loneliness.

For patients with mental health conditions, mental healthcare teams are often the primary point of interaction

Table 5 Engagement in Protective Measures Since COVID-19 Among Medicare Beneficiaries With and Without a Self-reported History of Depression

\begin{tabular}{|c|c|c|c|c|}
\hline & \multicolumn{4}{|l|}{ (Weighted \%)* } \\
\hline & $\begin{array}{l}\text { Total survey population } \\
(\mathrm{n}=\mathbf{1 1 , 0 8 0 )}\end{array}$ & $\begin{array}{l}\text { Medicare beneficiaries with self- } \\
\text { reported depression } \\
(\mathrm{n}=\mathbf{3 0 1 9 )}\end{array}$ & $\begin{array}{l}\text { Medicare beneficiaries without } \\
\text { self-reported depression } \\
(n=8061)\end{array}$ & $\begin{array}{l}P \\
\text { value }\end{array}$ \\
\hline $\begin{array}{l}\text { Washed hands for } 20 \text { seconds } \\
\text { with soap and water }\end{array}$ & 96.5 & 96.7 & 96.4 & 0.41 \\
\hline $\begin{array}{l}\text { Avoided contact with sick } \\
\text { people }\end{array}$ & 96.0 & 96.3 & 95.9 & 0.46 \\
\hline Wore facemask & 95.4 & 95.2 & 95.4 & 0.68 \\
\hline Kept 6 feet distance & 95.0 & 94.5 & 95.2 & 0.26 \\
\hline $\begin{array}{l}\text { Avoided gatherings of } 10+ \\
\text { people }\end{array}$ & 92.2 & 92.9 & 92.0 & 0.15 \\
\hline Used sanitizer & & & & 0.91 \\
\hline Yes & 89.8 & 89.7 & 89.8 & \\
\hline No & 9.4 & 9.5 & 9.4 & \\
\hline Unable due to shortage & 0.8 & 0.8 & 0.8 & \\
\hline Sheltered in place & 86.4 & 89.1 & 85.5 & 0.001 \\
\hline $\begin{array}{l}\text { Coughed/sneezed into tissue/ } \\
\text { sleeve }\end{array}$ & 79.9 & 80.9 & 79.6 & 0.24 \\
\hline Cleaned common areas & 75.7 & 76.8 & 75.3 & 0.17 \\
\hline Avoided touching face & 74.9 & 74.3 & 75.1 & 0.47 \\
\hline
\end{tabular}


with the larger healthcare system. ${ }^{4}$ Mental health teams are ideally positioned to help patients navigate barriers in access to care and facilitate communication and collaboration between primary care and mental healthcare teams. Lastly, the impact of social isolation may propagate poorer mental health, highlighting the importance of continued patient engagement through telehealth and phone visits. ${ }^{4}$

As federal regulations and state policies continue to develop to mitigate the health and economic needs of COVID-19, it is imperative to consider how vulnerable populations, such as older adults with mental health conditions, will be impacted. This includes efforts to increase access to care through expansion of broadband internet, housing support such as antieviction policies, and nutritional assistance support. ${ }^{29-32} \mathrm{Ad}-$ ditionally, in 2017, the Accountable Health Communities and Comprehensive Primary Care launched waiver programs and managed care organizations that paid to meet social needs and complex care needs of its beneficiaries. ${ }^{33}$ These programs may improve access to care, remove structural barriers, and improve patient-centered outcomes.

\section{Limitations}

There are several limitations to consider when interpreting our study. First, responses were all self-reported, which may increase recall and social desirability biases. Next, as this was a stand-alone supplement to the MCBS, a current diagnosis of depression was not ascertained at the time of the survey, but reported based on beneficiaries' response in the fall 2019 MCBS. However, because of this limitation, our findings likely represent conservative estimates of the association between depression and access to care and outcomes of care, since only a self-reported history of depression was collected and there was no information on whether current symptoms existed or if symptoms developed during the pandemic. In addition, our study focused on Medicare beneficiaries and may not be generalizable to other populations. Finally, our analysis focused on the risks associated with a history of depression, and while we accounted for other measures of vulnerability, such as age, income, comorbidities, and race in our analyses, these measures deserve further scrutiny as independent predictors of risk.

\section{Conclusion}

A self-reported history of depression among Medicare beneficiaries was associated with greater inability to access care, more unmet social and economic needs, and worse mental health outcomes, suggesting these individuals are at greater risk for adverse health outcomes because of COVID-19. Further research is needed to elucidate and mitigate these disparities for patients with mental health conditions. It is urgent to find interventions that aid in addressing access to medical care, unmet social needs, and mental health, which may be beneficial for patients with a history of depression.
Supplementary Information The online version contains supplementary material available at https://doi.org/10.1007/s11606-02106990-4.

Acknowledgements: This study is dedicated to Marjorie S. Rosenthal MD, MPH.

Corresponding Author: Lilanthi Balasuriya, MD; Yale National Clinician Scholars Program, Yale School of Medicine, New Haven, CT, USA (e-mail: lilanthi.balasuriya@yale.edu).

\section{Declarations:}

Conflict of Interest: Dr. Balasuriya is supported by the Yale National Clinician Scholars Program and U.S. Department of Veterans Affairs (VA) Office of Academic Affiliations through the VA/National Clinician Scholars Program and Yale University. These views do not in any capacity represent the federal government or the VA.

Dr. Quinton is supported through the UCLA National Clinician Scholars Program, Department of Medicine, and CTSI grant number 5TL1TR001883-04 and consults for UnitedHealthcare not related to this work or publication.

In the past 36 months, Dr. Ross has received research support through Yale University from Johnson and Johnson to develop methods of clinical trial data sharing, from Medtronic, Inc. and the Food and Drug Administration (FDA) to develop methods for postmarket surveillance of medical devices (U01FD004585), from the Food and Drug Administration to establish Yale-Mayo Clinic Center for Excellence in Regulatory Science and Innovation (CERSI) program (U01FD005938), from the Blue Cross Blue Shield Association to better understand medical technology evaluation, from the Centers of Medicare and Medicaid Services (CMS) to develop and maintain performance measures that are used for public reporting (HHSM-500-2013-13018I), from the Agency for Healthcare Research and Quality (RO1HSO22882), from the National Heart, Lung and Blood Institute of the National Institutes of Health (NIH) (RO1HSO25164), and from the Laura and John Arnold Foundation to establish the Good Pharma Scorecard at Bioethics International and to establish the Collaboration for Research Integrity and Transparency (CRIT) at Yale.

\section{REFERENCES}

1. National Institute of Mental Health. Individual Mental and Behavioral Disorders for U.S. https://www.nimh.nih.gov/health/statistics/disability/individual-mental-and-behavioral-disorders-for-us.shtml. Accessed December 12, 2020.

2. Blazer DG. Depression in late life: review and commentary. $J$ Gerontol A Biol Sci Med Sci. 2003;58(3):249-265.

3. Druss BG, Bradford WD, Rosenheck RA, Radford MJ, Krumholz HM. Quality of medical care and excess mortality in older patients with mental disorders. Arch Gen Psychiatry. 2001;58(6):565-572.

4. Druss BG. Addressing the COVID-19 Pandemic in Populations With Serious Mental Illness. JAMA Psychiatry. 2020;77(9):891-892.

5. Jung SE, Kim S, Bishop A, Hermann J. Poor Nutritional Status among Low-Income Older Adults: Examining the Interconnection between SelfCare Capacity, Food Insecurity, and Depression. $J$ Acad Nutr Diet. 2019;119(10):1687-1694.

6. Pirrie M, Harrison L, Angeles R, Marzanek F, Ziesmann A, Agarwal G. Poverty and food insecurity of older adults living in social housing in Ontario: a cross-sectional study. BMC Public Health. 2020;20(1): 1320.

7. Compton MT SR. The Social Determinants of Mental Health. 2015.

8. Gellad WF, Grenard JL, Marcum ZA. A systematic review of barriers to medication adherence in the elderly: looking beyond cost and regimen complexity. Am J Geriatr Pharmacother. 2011;9(1):11-23.

9. Banerjee D. 'Age and ageism in COVID-19': Elderly mental health-care vulnerabilities and needs. Asian J Psychiatr. 2020;51:102154.

10. Banerjee D. The impact of Covid-19 pandemic on elderly mental health. Int J Geriatr Psychiatry. 2020. 
11. Benfer EA WL. Health Justice Strategies To Combat COVID-19: Protecting Vulnerable Communities During A Pandemic. https://www. healthaffairs.org/do/10.1377/hblog20200319.757883/full/?utm campaign=H. Accessed October 19, 2020.

12. Raifman J, Bor J, Venkataramani A. Unemployment insurance and food insecurity among people who lost employment in the wake of COVID-19. medRxiv. 2020.

13. One in Four Older Adults Report Anxiety or Depression Amid the COVID19 Pandemic. https://www.kff.org/medicare/issue-brief/one-in-fourolder-adults-report-anxiety-or-depression-amid-the-covid-19-pandemic/ . Accessed December 20, 2020.

14. Troutman-Jordan M, Kazemi DM. COVID-19's impact on the mental health of older adults: Increase in isolation, depression, and suicide risk. An urgent call for action. Public Health Nurs. 2020;37(5):637-638.

15. Centers for Medicare and Medicaid Services MCBS Public Use File. https://www.cms.gov/Research-Statistics-Data-and-Systems/Downloadable-Public-Use-Files/MCBS-Public-Use-File. Accessed November 19, 2020.

16. Medicare Current Beneficiary Survey. 2020 Data User's Guide: COVID-19 Summer Supplement Public Use File. https://www.cms.gov/files/document/2020mcbscovidpufsummerdug.pdf. Accessed Noveber 11, 2020

17. Ostrow L, Manderscheid R, Mojtabai R. Stigma and difficulty accessing medical care in a sample of adults with serious mental illness. $J$ Health Care Poor Underserved. 2014;25(4):1956-1965.

18. Yamada T, Chen CC, Murata C, et al. Access disparity and health inequality of the elderly: unmet needs and delayed healthcare. Int $J$ Environ Res Public Health. 2015;12(2):1745-1772.

19. Niefeld MR, Kasper JD. Access to ambulatory medical and long-term care services among elderly Medicare and Medicaid beneficiaries: organizational, financial, and geographic barriers. Med Care Res Rev. 2005;62(3):300-319.

20. Kim EH, Gellis ZD, Bradway CK, Kenaley B. Depression care services and telehealth technology use for homebound elderly in the United States. Aging Ment Health. 2019;23(9):1164-1173.

21. Novak P, Sanmartin MX, Ali MM, Chen J. Health Conditions Associated With Severe Illness From COVID-19 Among Individuals With Serious Mental Illness. Psychiatr Serv. 2020:appips202000300.

22. Willis DJ. Introduction to the special issue: economic, health, and mental health disparities among ethnic minority children and families. $J$ Pediatr Psychol. 2002;27(4):309-314.

23. Li L, Li F, Fortunati F, Krystal JH. Association of a Prior Psychiatric Diagnosis With Mortality Among Hospitalized Patients With Coronavirus
Disease 2019 (COVID-19) Infection. JAMA Netw Open. 2020;3(9):e2023282.

24. Wang Q, Xu R, Volkow ND. Increased risk of COVID-19 infection and mortality in people with mental disorders: analysis from electronic health records in the United States. World Psychiatry. 2020.

25. Substance Abuse and Mental Health Services Administration. Disaster and Serious Mental Illness. https://www.samhsa.gov/sites/default/ files/disasters-people-with-serious-mental-illness.pdf. Accessed December $21,2020$.

26. Ettman CK, Abdalla SM, Cohen GH, Sampson L, Vivier PM, Galea S Prevalence of Depression Symptoms in US Adults Before and During the COVID-19 Pandemic. JAMA Netw Open. 2020;3(9):e2019686.

27. Ettman CK, Abdalla SM, Cohen GH, Sampson L, Vivier PM, Galea S Low assets and financial stressors associated with higher depression during COVID-19 in a nationally representative sample of US adults. $J$ Epidemiol Community Health. 2020.

28. Kaiser Family Foundation. The implications of COVID-19 for Mental Health and Substance Use. https://www.kff.org/coronavirus-covid-19/ issue-brief/the-implications-of-covid-19-for-mental-health-and-substance-use /\#: :text=The $\% 20 \mathrm{KFF} \% 20$ Health $\% 20$ Tracking\%20Poll, eating $\% 2 \mathrm{C} \% 20$ increases $\% 20$ in $\% 20$ alcohol $\% 20$ consumption. Accessed April 2nd, 2021.

29. U.S. Department of Agriculture. Broadband. E-Connectivity for All Rural Americans is a Modern-day Necessity. https://www.usda.gov/broadband. Accessed January 1, 2021.

30. Housing and Urban Development. Coronavirus (COVID-19). https:// www.hud.gov/coronavirus. Accessed January 1, 2021.

31. National Public Radio. New York Approves Eviction Moratorium Unti May. https://www.npr.org/sections/coronavirus-live-updates/2020/12/ 29/951042050/new-york-approves-eviction-moratorium-until-may. Accessed January 1, 2021.

32. U.S. Department of Agriculture. Food Assistance. https://www.usda. gov/coronavirus/food-assistance. Accessed January 1, 2021.

33. Powers BW, Modarai F, Palakodeti S, et al. Impact of complex care management on spending and utilization for high-need, high-cost Medicaid patients. Am J Manag Care. 2020;26(2):e57-e63.

Publisher's Note Springer Nature remains neutral with regard to jurisdictional claims in published maps and institutional affiliations. 